\title{
De cómo la escuela construye históricamente libertad con disciplina. Un guiño para pensar históricamente la relación paz y educación
}

How the School Historically Builds

Freedom with Discipline. A Way to Think about the Relationship between Peace and Education

\author{
Juan Carlos Echeverri Álvarez \\ Universidad Pontificia Bolivariana, \\ Medellin, Colombia. Facultad de Educación. \\ juan.echeverri@upb.edu.co
}

\begin{abstract}
Resumen
Se presentan tres escenas de escuela en Colombia en distintas épocas: primeras décadas del siglo XIX, segunda década del siglo xx, y el presente. Si bien en la primera se ve castigo, en la segunda una incipiente emancipación estudiantil, y en la tercera una escuela violenta, lo cierto es que las tres comportan excesos que imposibilitan percibir su realidad subyacente: no son la negación de una libertad ideal sino evidencias de la construcción del tipo de libertad que el liberalismo requiere para mantener su vigencia como forma general del poder. La discusión final es más teórica: si la escuela ha construido libertad en prácticas como el castigo, también puede construir la paz pese a que en la actualidad sea conflictiva, violenta y homofóbica. Se reconoce que "la escuela hace poco, pero hace", y, si gracias a ese poco la escuela ha construido libertades cada vez más visibles y hasta desbordadas, también generará prácticas y discursos para fundamentar mejores formas de la paz. Esta pregunta perentoria por la paz fuerza al artículo a concluir con la invitación a emprender una historia de la educación en clave ejercitante, porque la paz debe ser el ejercicio que produzca la habilidad de ser pacíficos.
\end{abstract}

Palabras clave: gubernamentalidad, paz, escuela, libertad, Colombia. 


\begin{abstract}
In this article three school scenes in Colombia from different time periods are presented: the first decades of the nineteenth century, the second decade of the twentieth century, and the present. Although in the first one is dominated by punishment, the second portrays an incipient student emancipation, and the third represents a violent school, the fact is that all three school scenes show excesses that make it impossible to perceive their underlying reality: they are not the denial of an ideal freedom, but they are evidence of the construction of the kind of freedom that liberalism requires to maintain its validity as a general form of power. The final discussion is more theoretical: if the school has built freedom in practices such as punishment in the past, it can also build peace despite being conflictive, violent and homophobic in the present. It acknowledges that "school does little, but it does something" and if, because of that, the school has built freedoms that are increasingly visible and even overflowing, it will also generate practices and discourses to support better forms of peace. This peremptory question for peace leads the article to conclude with the invitation to embark on a history of education as "exercise" - for peace should be the exercise that produces the ability to be peaceful.
\end{abstract}

Abstract

Keywords: governmentality, peace, school, freedom, Colombia

\title{
Introducción
}

El historiador de la educación, en épocas de bicentenario, no alcanza a ver en el pasado continuidades sino unidad de sentido de ciertas lógicas que mantienen su vigencia en procesos de transformación, refinamiento y exhaustividad. De tal manera, entre el presente de la escuela y su emergencia constitucional, a principios del siglo XIX, de los dispositivos fundamentales para garantizar sus transformaciones en el marco de una misma lógica de poder: la gubernamentalidad liberal puede identificarse un hilo conductor que, pese a los evidentes cambios y desplazamientos, muestra una lógica de gobierno de la población que ha recurrido históricamente a la educación en su forma escuela como uno.

El artículo asume las efemérides del bicentenario como pretexto para reflexionar la educación en clave de producción de libertad y de construcción de la paz. Pensar de qué manera se articula el pasado objeto de conmemoración con lo que se requiere ser en el presente y llegar a ser en el futuro. Hablar de producción de la libertad y de decantación de la paz no busca juntar con un pensamiento pasajero las dos puntas de una historia sin conexiones: por un lado, la independencia y su dimensión educativa, por el otro, el presente de la escuela en Colombia. Expresa, mejor, la posibilidad de pensar el significado de un proceso 
educativo y pedagógico que aún hoy, 200 años después, se mantiene como fundamento de una lógica todavía vigente: la de los Estados constitucionales en el marco del poder liberal.

Para concretar este pensamiento, el artículo recurre a tres escenas en tres tiempos diferentes dentro de un proceso de refinamiento del poder liberal. Una, en las primeras décadas del siglo XIX, la otra, en las primeras del siglo XX; y la última, en el presente del siglo XXI. Una es literaria, la otra de archivo y, la última, una conversación con una maestra de educación básica. Las tres permiten mostrar un hilo conductor: la construcción de subjetividades de la libertad durante estos doscientos años que, sin embargo, se descuida en favor de supuestas rupturas y superaciones (Echeverri, 2015). Es oportuno festejar las efemérides y, también, el arribo a una posible paz duradera. Sin embargo, frecuentemente "la fiesta conmemorativa y la ausencia de pensamiento se juntan en buena armonía.". El doble festejo, efemérides y paz, debe propiciar un pensamiento reflexivo sobre esa historia y sobre el presente para reconocer los mecanismos mediante los cuales hemos llegado a ser lo que somos en educación y sociedad.

Los azotes del profesor Fructuoso, la agresiva imprecación de viejo hijo de puta, y la intención de venganza de la maestra, no son, por sí mismos, expresión de la libertad; por supuesto que no. Son consecuencia de las condiciones históricas de producción de libertad que se imponen en contextos determinados y, además, expresión de demandas formuladas desde abajo para que se amplíen constantemente derechos otorgados más o menos tímidamente desde arriba. Solamente en condiciones de producción de un tipo de libertad particular se generan estos tres fenómenos que son, al mismo tiempo, la expresión y el exceso de la producción de la libertad en la escuela.

Esas tres escenas no hacen suponer que en la escuela se ha transitado de un vergonzoso pasado de castigos y encierros hacia un presente violento, homofóbico y discriminador. Nada hay de eso. Es necesario mirar detenidamente las escenas y reconocer en ellas el sustrato profundo que desvela la producción constante de la libertad como forma del gobierno de la población. Esa mirada atenta, además, reconocerá que la escuela, en aparentes lógicas de violencia, homofobia y falta de autoridad, puede construir la paz que demanda la sociedad porque ella misma es un ejercicio de inmunización contra enfermedades autodestructivas que atacan ciertas sociedades en el marco de la aventura vital humana. El ejercicio educativo en la escuela es la terapia de las sociedades para autorregenerarse.

En efecto, si en medio de prácticas disciplinarias la escuela ha construido la libertad necesaria para el gobierno de la población, aunque a primera vista esta libertad parezca en déficit o negada por excesos disciplinarios, esta misma escuela producirá a largo plazo la paz necesaria para vivir juntos, sin importar que la percepción actual sea que ella misma necesi-

1 "Un discurso conmemorativo no llega a ofrecer garantía alguna de que, en la fiesta conmemorativa, pensemos". (Heidegger, 1994: 24). 
ta pacificarse y ser intervenida. En este sentido, las tres escenas sirven para reconocer que la escuela en la sociedad "hace poco, pero hace", es decir, pese a sus aparentes excesos o carencias, coadyuva a producir transformaciones en relación con un ideal social, bien sea la producción de las libertades que nos gobiernan o la generación de una paz que haga posible la realización de esas libertades. En fin, esta pregunta por la paz lleva al artículo a concluir con la invitación a emprender una historia de la educación en clave ejercitante, puesto que la paz puede ser mirada como un ejercicio educativo permanente que produzca la habilidad de ser sociedades pacíficas.

\section{Tres escenas históricas de la escuela}

I. A las nueve y media volvíamos a entrar en la sala para que los tomadores dieran cuenta de las lecciones y darle a cada uno su merecido con arreglo a este sencillo código penal que estaba pegado en la columna del corredor: por cada punto un ferulazo, seis azotes a los que den pésima, seis más a los que se ensoberbezcan. Los tomadores poniéndose de pies hacían el papel de defensores o fiscales y don Fructuoso dictaba la sentencia [...] Apenas se pronunciaba esta horrible sentencia, dos patanes extendían una capa en uno de los rincones de la sala, otro cargaba al reo y el maestro con la impasividad de un antiguo cirujano, hacía zumbar el rejo y descargaba lentamente los seis furibundos azotes que todos los muchachos íbamos contando en voz baja (Carrasquilla, 1927).

II. El maestro Pereañez dijo al maestro Herrera, que tuviera la bondad de aislar a los alumnos que se le imponían, entre estos se encontraba un niño pequeño del Sr. Ricardo Ortiz; el alumno José Joaquín Ortiz, perteneciente a la sección superior, hermano de este y [...], viendo que a su hermano lo habían ordenado el director que pasara a un extremo del patio a hacer unos movimientos gimnásticos con otros alumnos dijo al director que 'se le ordenaba pasar a su hermano porque era pequeño, y que él solo no hacia bulla, en consecuencia le ordenó el director, salir de la fila e ir al lugar donde hacían ejercicios los primeros, este repuso: "salgo si me da la gana", diciendo en voz alta y en presencia de todos los alumnos presentes: "viejo hijo de puta"(AHAA Alcaldía, 1926).

III. Una maestra de la Educación Básica contaba que tenía en preescolar un "malparidito" de cinco años que la trataba de vieja hijueputa, les pegaba a los demás niños y había intentado pegarle a ella misma en varias oportunidades. Niño insoportable que ni podía tocar para evitarse problemas laborales y con la justicia. Debía seguir el debido proceso para hacerlo expulsar, como pretendía, lo que conllevaba anotaciones continuas y remisión a especialistas que determinaran su estado mental y capacidad socializadora. Mientras, contaba la maestra, cuando este niño estaba 
golpeando a una indefensa, ella, con sigilo, comisionaba a otro niño, mayor que él, para que los separara y, a su vez, le pegara una golpiza al abusador (conversación con una profesora de Educación Básica).

La evidencia de las escenas es contundente: desde el siglo XIX se ha dado un desplazamiento que da qué pensar sobre la escuela, la niñez y los maestros. Pero su secuencia no representa el tránsito entre un pasado remoto todavía rígido, disciplinario, de encierros y de castigos hasta su antípoda, es decir, una escuela indisciplinada y violenta que consume su energía en esfuerzos para que la niñez y juventud la habiten pacíficamente. Por el contrario, los tres momentos hacen parte de una misma lógica de poder: la gubernamentalidad liberal. Cada una es un refinamiento en la producción constante de la libertad que esta forma del poder necesita para su mayor exhaustividad y permanente viabilidad. Es decir, no existe un tránsito desde la colonia, como una zona de libertad secuestrada, hasta otro punto en el presente que, por acumulación de cada vez más libertad, evidencia excesos de indisciplina y violencia.

¿Qué es la libertad en la gubernamentalidad?: "La libertad nunca es otra cosa — pero ya es mucho- que una relación actual entre gobernantes y gobernados, una relación en que la medida de la demasiado poca libertad existente es dada por la aún más libertad que se demanda" (Foucault, 2007: 83). La libertad se construye a diario en la relación entre derechos que potencian la acción y demandas constantes para ampliar más la libertad que esa acción posibilita y fuerza. Conquistar la independencia no fue llegar al reconocimiento de una supuesta libertad universal hasta ese momento secuestrada, sino reconocer los mecanismos mediante los cuales su fabricación se hace constante como mecanismo del gobierno de la población.

Gobernar es una práctica gubernamental consumidora de libertad que funciona con base en la existencia de libertades de mercado, del derecho de propiedad, de vender y de comprar, de discusión y de expresión. Por ser consumidora de libertad, la práctica gubernamental se ve abocada a producirla y organizarla. El liberalismo procura que haya la libertad suficiente para que los individuos y los grupos sean libres. En palabras de Foucault: "el liberalismo plantea simplemente lo siguiente: voy a producir para ti lo que se requiere para que seas libre. Voy a procurar que tengas la libertad de ser libre" (Foucault, 2007: 84).

El liberalismo habla de un juego según el cual, desde el punto de vista de gobierno, se debe dejar que la gente haga y las cosas transcurran:

Dejar hacer, pasar y transcurrir, significa esencial y fundamentalmente hacer de tal suerte que la realidad se desarrolle y marche, siga su curso de acuerdo con las leyes, los principios y los mecanismos que le son propios. [...] Se puede decir [...] que esta 
ideología de la libertad, esta reivindicación de la libertad fue sin duda una de las condiciones del desarrollo de las formas modernas o, si lo prefieren, capitalistas de la economía (Foucault, 2006: 70).

La libertad moderna supone una nueva forma de gobierno de la población. Es preciso aclarar, sin embargo, que la libertad no ha sido una consecuencia imprevista de la historia sino, por el contrario, la previsión de una forma de gobierno: la libertad tenía que ser inventada en los territorios del poder; así, para Friedrich von Hayek (1979): "El hombre no se ha desarrollado en la libertad [...] la libertad es un artefacto de la civilización [...] La libertad fue posible gracias a la evolución gradual de la disciplina de la civilización que es al mismo tiempo la disciplina de la libertad" (Rose, 2010: 67).

El triunfo de las artes liberales de gobierno fue hacer a la gente libre. Las personas eran liberadas en los reinos del mercado, de la sociedad civil y de la familia. La libertad no es un proceso natural del tránsito en la aventura vital de la especie humana, es una construcción consciente utilizada como instrumento mediante el cual se regularon estrategias y técnicas de gobierno al mismo tiempo que con estas se intentaba producir cada vez más libertad. En fin, la libertad ha sido en la modernidad un objetivo de gobierno, al mismo tiempo que es su instrumento constante, y la escuela el dispositivo para su creación constante. En palabras de Nikolas Rose: "La escuela era un lugar muy importante para la elaboración de las normas de la libertad [...] la invención de la escuela estaba vinculado a estas preocupaciones para producir la libertad bien regulada" (Rose, 2010: 76).

\section{Primera imagen: El método lancasteriano de enseñanza}

El método lancasteriano de enseñanza desde el siglo XIX ha sido lastrado en Colombia con escenas negativas de lobreguez, de castigos infamantes y de encierro (Caruso, Pineau y Dussel 2001; Caruso y Roldán, 2005). Estas escenas populares se fueron construyendo paulatinamente con base en argumentos que resaltan imágenes como las del profesor Fructuoso para sustentar localmente la idea foucaultiana según la cual, para finales del siglo XVIII, existía una forma general del poder nombrada como poder disciplinario "cuyo objetivo era moralizar a las clases pobres [...] habituándose a la subordinación y al freno" (Saldarriaga, 2003). Dentro de esta lógica de poder el método lancasteriano se ha presentado como una maquina escolar perfecta: 
Asociación de las técnicas disciplinarias y de estrategias económicas para educar, moralizar y someter a los "pobres". Un adiestramiento del cuerpo para la sumisión. No es la enseñanza mutua un método de enseñanza planteado al margen de la dominación, lleva inscrito hasta en sus formas más meticulosas de organización escolar la forma como las clases dominantes sometían el cuerpo, el conocimiento y la moral de los niños a un aprendizaje para la obediencia y el sometimiento (Zuluaga, 1979: 15).

El método fue un fenómeno concomitante con la expansión del liberalismo o, mejor, uno de los mecanismos para su expansión. No era un dispositivo para la sumisión de las mentes mediante la interiorización de ideas trascendentes que anquilosan la acción, sino una estrategia del poder para la construcción de la libertad básica para consolidarse como forma general del poder (Foucault, 2007; Deleuze, 1991; Agamben, 2016). La propagación mundial del método lancasteriano, durante la primera mitad del siglo XIX, fue el mayor ejemplo de la internacionalización de propuestas pedagógicas, y el primer intento a gran escala de educar las masas como fundamento de la legitimidad formal del poder. Proceso vinculado con las independencias americanas, con la invención de los nuevos Estados y con la creación de formas representativas de gobierno para la homogeneización de la población mediante la creación de una ciudadanía moderna capaz de superar la heterogénea, segmentada e "ignorante" población colonial (Caruso, Pineau y Dussel, 2001: 39).

El método utilizado en la mayoría de sistemas nacionales de enseñanza a principios del siglo xIx fue el "sistema mutuo de enseñanza" o método lancasteriano (Weinberg, 1983; Luzuriaga, 1969). El sistema también se ha conocido con el nombre de método monitorial, por la utilización de monitores para la enseñanza: estudiantes mayores y mejor preparados que podían enseñar a un número elevado de estudiantes de menor edad y menos entendidos. Tanto monitores como estudiantes eran estimulados mediante un complejo sistema de premios y de castigos (Manual, 1826) con la intención de, por un lado, abaratar los costos educativos de las masas populares; por el otro, mediante la repetición e inspección sistemática fijar la atención de los niños y obtener la memorización de los conocimientos (Zuluaga, 1984).

La escuela lancasteriana fue una concreción de la libertad liberal y el dispositivo privilegiado que la agenciaba, pues para la lógica republicana era tan importante producir un orden disciplinario como liberar a los estudiantes de la tradición colonial. A la escuela no ingresó la disciplina de la sumisión sino la disciplina de la libertad, porque la libertad exigía la disciplina de sacar a los niños de la subordinación vertical de una sociedad jerarquizada para insertarlos en la obediencia de leyes que fomentaban la autonomía, la movilidad y la competencia para generar el crecimiento constante de los individuos y de las naciones: la escuela, implícitamente repetía con el liberalismo: voy a crear las condiciones para que seas libre (Foucault, 2007: 84). 
La escuela era la máquina que juntaba a los niños y posibilitaba verlos de manera permanente. El encierro producía contactos, inclusiones y aprendizajes, les otorgaba una voz y les garantizaba visibilidad para convertirse en objetos de saber y de poder: escenario privilegiado para transformar la mentalidad de los pobladores en relación con el papel que cada persona tenía en la nueva sociedad. Paradójicamente, el encierro mismo era expresión de la libertad: enajenación de los hijos a los padres para, años después, devolverlos a la sociedad siendo diferentes de lo que hubieran sido en los ámbitos del hogar, del púlpito y del trabajo. Esto es, ciudadanos que reconocen fundamentalmente la ley constitucional como ordenadora de la vida en sociedad (Echeverri, 2015).

Al mismo tiempo que encerraba, la escuela fue la receptora de todas las castas, clases y colores bajo ideas de igualdad. ${ }^{2}$ Ubicar juntos a los niños de todos los colores en el mismo lugar para aprender las mismas cosas fue un acto de igualdad inconmensurable, porque, antes, durante la colonia, fue: "condición que en la dicha escuela no se puedan recibir indios, negros, mulatos, ni zambos, porque (el) ánimo deliberado y voluntad expresa es excluirlos y que solo reciban pobres españoles y los demás que no sean prohibidos" (Hernández De Alba, 1976: 356). Incluso, mucho tiempo después de esta restricción, en el último cuarto del siglo XVIII, cuando apenas se comenzaba a recibir castas al mismo tiempo que blancos, la escuela mantenía las jerarquías sociales porque era: "una separación y una subordinación, en la que se enseña(ba) a su vez a los niños de la plebe a guardar respeto y sumisión a los de la nobleza" (Martínez, 1986: 70).

La escuela republicana, en tal sentido, liberaba de una realidad anterior para sujetar a la nueva forma del poder. En ella comenzaban a establecerse y a circular prácticas y discursos que iban a garantizar la formación de nuevas personas en concordancia con la realidad política. Las diferencias en el ingreso a la institución, la posición dentro de la escuela y del salón de clase cada vez iban a estar menos en relación con el color de la piel u otro tipo de dignidades, y cada vez se relacionaría más con el desempeño individual.

En la escuela republicana, la diferencia entre los niños era de riqueza-pobreza. El liberalismo no era la estrategia para hacerla equitativa: "No concurrieron todos los niños que debían haber concurrido al examen, porque aquella fracción es generalmente de proletarios tales que muchos no tienen un vestido con que presentarse moderadamente cubiertos" (AHA Gobierno Provinicial, 1856. T. 1806). Sin embargo, la pobreza, al mismo tiempo que un obstáculo, era la potencia competitiva que generaba acción social en un mundo regido por el mercado. En la escuela, el niño pobre podía acortar distancias y lograr reconocimiento mediante el esfuerzo personal en un nuevo mundo competitivo que no se otorga, sino que se conquista (Manual, 1826).

2 Para el sistema lancasteriano, véase Zuluaga, 2001; Sanabria, 2010; Caruso, 2005; Báez, 2006. 
La escuela liberó al niño de yugos ancestrales. Le otorgó un espacio diferente al que exigía brazos para el trabajo familiar. La escuela obligaba el encierro para liberar a los niños de las arduas labores que se les imponía en la administración de la pobreza de casa familiar: encerrarlos era visibilizarlos y liberarlos, al convertirlos en seres observables, objetos del saber y del poder:

[...] para difundir la Instrucción Pública, tiene que lucharse contra la resistencia de los padres de familia a educar a sus hijos impuesto por hábitos inveterados, o ya tal vez por la necesidad que los obliga a dedicar todos los miembros de su familia como brazos auxiliares de las duras labores del campo de que ordinariamente derivan su subsistencia (Informe, 1883: FM/ 272).

La escuela liberaba a los niños de una forma paradójica. En una sociedad cada vez más inmersa en nuevas concepciones del trabajo y en el marco de leyes que imponían esas nuevas éticas laborales, por ejemplo, mediante el castigo de la vagancia, el encierro escolar durante buena parte del día, todos los días, liberaba a los niños de la libertad sin control de la desocupación. Una población pobre en centros urbanos con una cantidad creciente de niños sin oficio destinada a perturbar las calles:

Jornaleros, oficiales y maestros [...] dejan diariamente abandonados a sus mejores hijos en las calles y en las plazas, pidiendo limosna con necesidad y sollozos y con la molestia de cuantos encuentran en ellos, estos niños criados en la ociosidad, madre de todos los vicios, se acostumbran a ella y al mal ejemplo de los vagos y delincuentes, de quienes aprenden todo lo malo (Martínez, 1994: 187).

La escuela recibía a estos niños y les otorgaba un oficio generalizado: el oficio de ser infancia escolarizada, es decir, estudiantes. Un oficio y un interés que les daba una posición diferente al de la vagancia o de la invisibilidad precaria de los hogares en el campo, los formaba para ser libres, es decir, "que obedece(n) sólo a la ley, que no está(n) sujeto(s) al capricho y a las pasiones de los depositarios del poder. Un pueblo es libre cuando no es juguete del que manda, y cuando solo manda la ley" Firman: José Joaquín Camacho y Francisco José de Caldas. (Diario Político de Santa Fé, 1810)

El método lancasteriano antes que ser la estrategia de encierro, vigilancia y castigos fue el instrumento para la conversión de súbditos en ciudadanos. En la máquina disciplinaria, la presencia del castigo, antes que mostrar una aplicación sistemática e infamante, en vez de caracterizar la forma cotidiana de estar en la escuela, muestra los esfuerzos constantes para morigerar su necesaria aplicación con conceptos pedagógicos (Martínez, 1986). El recuerdo de Carrasquilla con el maestro Fructuoso es la evidencia de castigos concretos que todavía 
atravesaban la escuela como excesos, pero también la retórica que se sumaba a los esfuerzos para combatirlos. Cada evidencia de castigo debe leerse menos como la evidencia de su existencia fáctica, y más como ejemplo de lo que intentaba superarse por ser un rezago colonial anquilosante. La denuncia por su persistencia llegaba hasta la prensa literaria y política de la época:

Todavía azotan a los niños en nuestras escuelas y ustedes señores que ofrecieron censurar todo lo que pareciese reprensible por qué no descargan el látigo sobre estos maestros de latinidad que quieren enseñar una lengua que quizá no saben, como pudiera un jinete de coraje hacer entrar en la andadura a su caballo (El Fósforo, 1823: 52).

Por los derechos que promulgaba, por los castigos que morigeraba y por el reconocimiento que hacía de los niños como objeto de saber, el sistema lancasteriano, al contrario de una máquina disciplinaria apabullante, le puso carne de niño a esas escuelas, es decir, puso desorden, desobediencia, riñas, chantajes, inasistencias, cambios de roles, presencia constante y competencia sostenida (Manual, 1826). En palabras de Olga Zuluaga: "su marcha —la de la disciplina - se descomponía con el azar de la infancia, capaz de descodificar con la risa y el juego los movimientos de la máquina” (Zuluaga, 1984: 89).

\section{Segunda imagen: viaje hacia el sí mismo y horizontalización de las relaciones ${ }^{3}$}

La imagen del joven estudiante, procaz con su maestro y adulto, capaz de tratarlo de viejo hijo de puta, contrasta con la imagen de un castigo permanente y vejatorio. Contrariamente, el castigo mismo se asemeja más a la kinésica que promociona la idea de una mente sana en un cuerpo sano; además, la sumisión parece trastocarse en insolencia. Para que esta imagen se diera, se estaba produciendo un desplazamiento que puede rastrearse como el paso del método lancastariano al pestalozziano y, luego, que se decanta en la Escuela Activa: es un desplazamiento de la pedagogía como ejercicio del gobierno sobre los cuerpos para iniciar el largo camino hacia el sí mismo y, por esta vía, horizontalizar las relaciones en un tipo de

\footnotetext{
${ }^{3}$ Podría pensarse que ese comportamiento era frecuente en esta "sección superior", por lo tanto, su previsibilidad le resta efecto argumentativo. Empero, se muestra que esa práctica es inducida mediante mecanismos de producción de libertad que abarca todos los niveles escolares. El refinamiento de estos mecanismos desplaza la violencia hasta una niñez obligada a ser cada vez más libre. Las escenas, en su conjunto, en vez de intentar recrear individualmente épocas determinadas, generan la imagen de ese desplazamiento desde una disciplina inapelable hasta la falta de autoridad de los maestros, y la violencia escolar.
} 
sociedad en la cual el mercado necesita uniformar la sociedad para hacer sujetos individuales, es decir, consumidores (Echeverri, 2015).

El sistema pestalozziano, introducido en Colombia a mediados del siglo XIX (Saldarriaga, 2003), fue un refinamiento de la gurbernamentalidad liberal en relación con el lancasteriano; la Escuela Activa lo fue en relación con el pestalozziano. Una vuelta de tuerca fundamental en proceso de construir la libertad: de la apropiación de los derechos y de la igualdad ante la ley; es decir, ante las expresiones externas de la construcción de la ciudanía, Pestalozzi planteó la posibilidad de ir más allá: planteó la construcción de la libertad desde el punto de vista del individuo en vías de ser sujeto, propone hacer un viaje hacia el sí mismo por la vía de la intuición (Pestalozzi, 1997, Saldarriaga, 2003).

Con su intervención sobre ésta no se busca tener influjos externos sobre los cuerpos por vía disciplinaria sino dentro de las mismas personas, en un intangible profundo. La libertad liberal no sólo requería un marco social para su ejercicio sino una intención individual de ejercerse y la demanda incesante para su ampliación continua: no sólo un efecto del derecho sino una forma mental de habitar la sociedad. La libertad comenzó a fundamentarse en el sujeto como una tecnología del yo: hacer vivir la experiencia de la libertad y sentirla indefinidamente en términos subjetivos: relación imaginaria con ellas capaz de superar, incluso, su negación concreta en las formas reales de vida (Foucault, 2008). En adelante la libertad necesitaría incrementarse, transformar el estatuto de las personas en la sociedad, y de cada quien consigo mismo: la libertad tenía que ser una necesidad vital, no simplemente un marco jurídico, un ideal o una promesa (Rose, 2010).

La libertad en la escuela se expresaría en preceptos pedagógicos y prescripciones que producían prácticas específicas, interpretaciones, modos de decir y hacer en la escuela que le daban existencia, voz y dignidad a los niños para constituirlos en sujetos; que les otorgaba un papel diferente al del maestro en el proceso de enseñanza, y forzaba modos diferentes de relacionarse con ellos: modos ya no absolutamente dependientes del aparato disciplinario sino forzados por dignidades cada vez más horizontales entre dos sujetos que se igualaban en las lógicas del derecho y de la pedagogía. El método pestalozziano buscaba transformar las concepciones en torno de lo que eran los niños, la escuela y el mismo proceso de la enseñanza: una forma de horizontalizar las dignidades de maestros y alumnos, es decir, de producir más libertad para los alumnos (Echeverri, 2015).

Un elemento fundamental de la libertad en el método pestalozziano fue el reconocimiento del otro como sujeto de derecho. Se pensaba que el deseo de la educación estaba presente en los niños, pero las formas institucionalizadas de impartirla terminaban por destruir este deseo innato. En cierta forma daba inicio la constante culpabilización del sistema educativo y del maestro en relación con un niño nunca suficientemente comprendido. 
Otra manera liberal de producir la libertad en la escuela por la vía de la culpabilización de quienes deberían ser los agentes de la ley:

En el niño no hay necesidad de despertar el deseo de la instrucción, él tiene este deseo, él tiene curiosidad; pero si es necesario instruirlo complaciéndolo, porque de otro modo se fastidia con la instrucción y la rechaza; y en este caso, apelar a castigos dolorosos es hacerla aborrecer todavía más. Bien pudiera sentarse como regla general, que cuando la enseñanza no es agradable a los niños, es porque se ha equivocado el modo de darla, o porque es demasiado elevado para ellos el asunto sobre que versa (El Preceptor,1877, núm. 2)

La escuela era un dispositivo para la adecuación del "espíritu correcto" en el marco general de la gubernamentalidad liberal. Reconocían también que se requerían "reglas especiales de que el maestro pueda hacer uso para mantener el orden en las escuelas, sin las cuales no podría absolutamente dar enseñanza alguna" (La Escuela Primaria, 1873, núm. 79). Estas adquirieron otra dirección y objetivo: no la verticalidad disciplinaria para fundar un orden escolar y social, sino articulada con más elaborados conocimientos pedagógicos en torno de lo que el niño era como individuo para producir más refinadas prácticas en la escuela, y con expertos que iban a prescribir alrededor del niño y la escuela (Rose, 2010; Varela, 1995).

La escuela requería de maestros que se apropiaran esos saberes para reconocer al niño como un miembro de la sociedad con derechos, es decir, un futuro ciudadano; un maestro que ya no concibiera su función en la escuela como un poder que fijaba su dignidad por el carácter de su posición, sino por su saber y por el conocimiento de lo que era él mismo como maestro y el niño como persona y alumno: conocimiento que le da mayor valía al alumno y le restaba protagonismo al maestro. El gobierno de la población escolar no era más una posibilidad inherente a la máquina disciplinaria, sino la consecuencia de la reconfiguración de su función: "el maestro que haya logrado establecer el hábito de la atención y la disciplina es sus alumnos ha logrado el gran paso del arte pedagógico" (El Pestalozziano, 1876, núm. 18).

La pedagogía era un arte para crear las condiciones de disciplina sin imponerla desde arriba mediante el juego simple de los premios y de los castigos. Contra estos se mantuvo una lucha constante: "se prohíbe al sr. director el uso de la palmeta para castigo de los niños, y se le advierte que los únicos castigos que puede usar son el arresto por pocas horas y posiciones forzadas propias de los niños" (AHAA 1882, 5 de agosto).

Si se quería hacer libres y moralmente contenidos a los niños, los maestros necesitaban esas mismas características. A los niños no se les obligaba por la fuerza a cumplir con las normas. La imagen que debían construir los niños del maestro no era la del autoritarismo vertical sino la de otra persona con derechos y dignidad diferentes, expresión de un poder como potencia y no como negación; en la escuela el niño debía poder comprender "que la autoridad del 
maestro era la expresión de la ley y el poder tutelar que vela(ba) por las necesidades del bien general, y protege(ía) los intereses de todos" (La Escuela Normal, 1874, T. 2).

El maestro fue el objeto de intervención, de prescripción y de exhortaciones a su vocación: se convertía por este camino en protagonista del proceso educativo. Sutilmente perdía su poder al mismo tiempo que pasaba a ser el protagonista: no era cualquier sujeto ni poseía cualquier tipo de conocimiento, era alguien con una misión específica en la constitución de la gubernamentalidad en relación con los más recién llegados a ella, potencia y obstáculo a la vez:

La mayoría de los maestros de escuela creen que el estado que abrazan es solamente como otro cualquiera de ganar la vida [...]. Muchos piensan que cuidándose tan sólo de la lectura, la escritura y cálculo, han cumplido con sus deberes: se engañan; su misión debe ser la de un padre. (El Repertorio Escolar, 1870).

El método pestalozziano aumentó la literatura prescriptiva para cualificar las prácticas del maestro y generarle una sujeción imaginaria y permanente con su quehacer. Literatura que denunciaba sus carencias, pero, de modo paralelo, exaltaba su función, le fijaba reglas y le recordaba constantemente su compromiso con la profesión, con los estudiantes, con la escuela y con la sociedad. Se produjo un desplazamiento de la posición del maestro y de las relaciones que a través de éste se establecían en la escuela: una posición nueva dentro de estrategias para la construcción de mayores espacios de libertad en el marco de las prácticas educativas cotidianas, en las cuales los maestros otorgaban mayor espacio y reconocían a los estudiantes como potencias de ciudadanía en relación con su propia intervención en ellos. En el maestro tendrían que converger:

La energía del mandatario con la dulzura del amigo, porque si falta lo primero los niños se burlarán de sus órdenes y si falta lo segundo verán en él el verdugo a quien temen y de quien podrán burlarse en la primera ocasión favorable. Importa además que los niños tengan más justo en complacer al director que miedo a sus castigos, pues no es el temor, sino el amor el móvil más noble de las acciones humanas ( $E$ I Pestalozziano, 1876, núm. 17).

La transformación de la relación con el niño, sus derechos adquiridos y distancia en relación con el poder del maestro, produjo un efecto de normalización constante del maestro para que transformara la idea que tenía de sí mismo y de su quehacer. Se desplazaba, por la vía de la literatura prescriptiva de la escuela, y en las dinámicas escolares, lo que había sido responsabilidad del alumno a la capacidad o incapacidad del maestro y de su arte de enseñanza. Como dijimos más arriba, a fomentar la idea constante de culpa en relación con sus estudiantes (López y Echeverri, 2006). 
La cuestión más difícil quizá que pueda presentar en la escuela es la de los castigos. Generalmente se cree que los niños son los culpables cuando tiene que sufrir alguna pena. Yo me atrevo a asegurar que el maestro es el responsable de más de la mitad de los castigos que impone a sus alumnos (Escuela Primaria, 1873, núm. 8).

En la escuela todos eran iguales ante el reglamento estudiantil, es decir, ante la ley, sólo la relación que el estudiante establezca con ésta determinará las mejores o peores formas de estar en ella. El precedente inmediato de la Escuela Activa en Colombia fue la crítica "al fiasco pedagógico de los sabios, historiadores, gramáticos y filólogos del siglo XIX" (Uribe, 1927: x), que se plasmó en la Ley Orgánica de Instrucción Pública de 1903. Una ley que buscaba de alguna forma producir un cambio en relación con la formación del método pestalozziano, el cual, supuestamente, había caído en un memorismo exagerado y un verbalismo sin razonamiento. En efecto, se querían incorporar métodos:

Que le hagan la guerra al verbalismo, a la enseñanza meramente libresca; que supriman todo intermediario entre la inteligencia de los niños y los objetos de estudio; que susciten la curiosidad y exciten la reflexión; que les permitan adquirir y asimilar las nociones morales y científicas que deben aprender (Uribe, 1927: XXv).

Se estaba transitando por un programa de libertad liberal: desprenderse de viejas sujeciones, adquirir independencia, autonomía, movimiento y relaciones. Los constreñimientos de la individualidad libre antes estuvieron referidos a la máquina disciplinaria, al castigo, a la verticalidad autoritaria del maestro; ahora, superadas esas limitaciones, se pedían liberaciones más sutiles: la repetición que impedía pensar, la limitación al libro que esquematizaba el conocimiento, los intermediarios anquilosantes, y la posibilidad de relaciones y de movimientos menos controlados y limitados. Lo que le criticaban los promotores de la Escuela Activa a la pedagogía pestalozziana era su ignorancia de las nuevas concepciones en torno de la infancia y su funcionamiento psicológico, así como su régimen disciplinario y su aislamiento de la sociedad (Sáenz, Saldarriaga y Ospina, 1997: 52).

La Escuela Nueva produjo efectos de libertad que no se presentaron como transformaciones fácilmente identificables sino modulaciones, profundizaciones, desplazamientos apenas perceptibles, en unos casos y, en otros, con mayor visibilidad en los discursos educativos. Época en la cual los saberes expertos profundizaban en la idea del "libre y espontneo desarrollo del alumno", al mismo tiempo, en la Escuela Activa la enseñanza no quedaba constreñida el método sino que lo utilizaba "para despertar la curiosidad, para ganar el aire libre, para crear una disciplina interna y un espacio de libertad, para colocar al maestro como guía espiritual." (Ardila y Vizcaíno, 2008: 293). 
A diferencia de los métodos anteriores, con la Escuela Activa el método no es camisa de fuerza pues cambia en relación con el objetivo supremo de la formación: la liberación pedagógica de los niños: "por fin el niño es el centro de todas las preocupaciones en la escuela. ¡Por fin el niño es un sol!” (Cubillos, 2007: 232). La Escuela Activa presentaba el siglo Xx como el del descubrimiento del niño. La escuela debía ser reorganizada en relación con ese hallazgo: ampliar la libertad posible en relación con sus necesidades. No sólo la psicología se adentraba más en el ya largo viaje emprendido hacia el sí mismo, sino que el ambiente en general debía ser alegre, convertir su entorno escolar en un jardín para que perdiera su imagen lóbrega y de cuartel. En la escuela alumnos y maestros: "constituyen dos fuerzas que se compenetran para formar un armonioso conjunto que tienda al desenvolvimiento de un ser que aporta muchas singularidades, conclusivas, propias, que han de ser respetadas por el instructor, convertido en hábil y profundo psicólogo" (Belalcazar, 1935: 62).

Según esta lógica, "el maestro deber(ía) subordinar su personalidad en pro del desarroIlo del niño" (Belalcazar, 1935: 62). Las nociones de autoridad, castigo, disciplina, orden, van reconfigurando en relación con la consolidación de la infancia como compuesta por personas con derechos, individuos con formas de conocer, saber, con su propio valor intrínseco.

Al mismo tiempo que se morigera el castigo, las relaciones entre profesores y estudiantes comienzan una más clara tendencia hacia la horizontalización. Al maestro se le va enredando la autoridad en el marco de los derechos y de los saberes que ingresan a la escuela. Todavía castiga, no cabe duda, pero esos castigos cada vez están más referenciados a violaciones más graves, mientras que las faltas leves se castigan con lo que es otra potencia formativa, como el ejercicio físico, por ejemplo. Por la vía del reconocimiento científico y legal del niño, el maestro comienza a ser culpable de no comprender suficientemente al niño. Así, entre el realce del niño y el enjuiciamiento constante del maestro comienza el proceso, que todavía no termina, de la escuela como un Estado de guerra que se hizo presumible con ese primer "viejo hijo de puta" en la boca de un estudiante (Echeverri, 2011; 2015).

\section{Tercera imagen: la escuela indisciplinada}

La escuela actual se presenta en términos de conflicto, violencia, falta de autoridad, necesidad de programas de convivencia ciudadana, prevención temprana de la violencia, medicalización de los niños, matoneo o acoso, entre otros fenómenos escolares. Paralela a esta violencia crecen las demandas por democratizar la escuela, la necesidad de una mejor formación ciudadana para que alcance mayores cuotas de libertad y de autonomía, único remedio para aliviar los males de una escuela que cargaba todavía el pesado fardo de una tradición autoritaria, vertical y disciplinaria heredada del siglo XIX (Cajiao, 1994; Castillo y Sánchez, 2003). 
La educación escolarizada gira hacia el niño como centro del proceso formativo: sujeto con derechos en ascenso en el marco de una sociedad en la cual el niño es su futuro previsible y, por lo tanto, el constante proyecto social y político que ha tenido su concreción legal más importante en la Constitución Política de 1991, como la vía legal para ampliar sus derechos en una sociedad que todavía no está a su alcance (García, 1996: 24). Supuestamente, para lograr la convivencia pacífica en la escuela es necesario aplicar un nuevo método de institución educativa que transforme la cultura escolar, tradicionalmente autoritaria, en otra cultura autónoma, modernizada, eficiente y fundamentalmente más libre y democrática (Castillo y Sánchez, 2003: 2).

Sin embargo, hay relación entre esas invocaciones a la democracia y las prácticas cotidianas que las hacen aparentemente necesarias. Esto es, entre ciertos fenómenos escolares (v.g., violencia, conflicto, falta de autoridad y medicalización) y la libertad invocada por conducto democrático hay un tipo de vinculación que no necesariamente establecía una relación según la cual la libertad democrática es, al mismo tiempo, el procedimiento y el objetivo para contar con una escuela más pacífica y, por lo tanto, con una mejor sociedad.

Evidencias de violencia y de excesos hace pensar que la concepción de niño y de joven que existe en la sociedad es la de sujeto de derecho protegido legalmente y convertido en el centro de la sociedad hasta el punto, tal vez excesivo, de propiciar la aparición de teorías que denuncian la aparente tiranía de la niñez y la infantilización de la sociedad (Vega, 2011). Un niño cada vez más protegido, más libre y autónomo, pero al mismo tiempo, más violento e indisciplinado en unas escuela y sociedad que parecieran confundir autoridad y autonomía en la relación que establece con sus niños y jóvenes (González, 1996).

La escuela ha dejado de ser el espacio rígido fundado por sociedades disciplinarias en un tiempo que dejó de ser el nuestro (Deleuze, 1991). En la escuela ya no se ve la máquina disciplinaria como control minucioso sobre los cuerpos, los tiempos, los espacios y la generalidad de las cosas pequeñas que constituyen la cotidianidad escolar. En la escuela actual no existen las disciplinas como: "métodos que permiten el control minucioso de las operaciones del cuerpo, que garantizan la sujeción constante de sus fuerzas y les imponen una relación de docilidad-utilidad" (Foucault, 1990: 141).

En la escuela actual la categoría de análisis es indisciplina (Echeverri, 2007; 2015). Esta marca su cotidianidad y reemplaza el conocimiento por esfuerzos socializadores. La escuela ha devenido escenario de violencia, receptora de campañas de convivencia, prevención temprana de la agresividad y, más recientemente, en espacio de terapias y medicalizaciones mediante las cuales se libera al maestro de su responsabilidad de agente de la ley y se le presenta como un simple mediador que ayuda a los escolares, y las familias, con la remisión de los niños a la autoridad inapelable de la medicina y la psicología (Varela, 1995). 
La escuela requiere de la resolución profesional de conflictos como una relación de paridad entre estudiantes y maestros que hace posible un espacio de tensiones en las cuales cada estamento tiene ideas estratégicas sobre su libertad y sus derechos (Jares, 1997). Espacio en el cual no es posible la verticalidad del castigo ni el uso de la fuerza, sino donde se recurre a formas sutiles de control mediante las cuales, pese a la sujeción que imponen, como en los casos de la terapéutica la experiencia de la libertad es cada vez más intensa y produce demandas de mayores cuotas de esa libertad.

Empero, la escuela, aunque conflictiva, indisciplinada y alejada del conocimiento científico y tecnológico, no carece de gobierno (Echeverri, López y Echeverri, 2007). La libertad es precisamente la forma de ese gobierno. Es decir, los conflictos, la violencia y los problemas de autoridad son las prácticas que objetivan un tipo de libertad específica en una sociedad y en una época determinadas, y no un precedente crítico que hace necesaria su invocación para llegar por fin a un supuesto estado ideal de democracia en el país. En síntesis, la libertad, y no la disciplina, es el elemento fundamental para comprender la escuela del presente (Rose, 2010).

El problema histórico de la escuela no tiene que ver con los supuestos rezagos de la máquina disciplinaria del siglo XIX, sino el concepto de libertad que circula socialmente para producir tipos específicos de subjetividades, de experiencias y de prácticas de libertad en la escuela:

\footnotetext{
En nuestra época, las ideas de la libertad han llegado a definir la base de nuestros sistemas éticos, nuestra práctica de la política y nuestros hábitos de la crítica. Por tanto, parece pertinente tratar de analizar las condiciones en que estas ideas de libertad y de estas prácticas en el nombre de la libertad han llegado a existir, y para aclarar las líneas de poder, la verdad y la ética que están en juego dentro de ellas (Rose, 2010: 10).
}

Es posible rastrear las relaciones entre esta forma de la libertad y la historia de la escuela en Colombia: analizar las prácticas concretas que históricamente han dado origen a formas de libertad en la escuela, y, en sentido inverso, las concepciones de libertad que producen diversos tipos de prácticas institucionalizadas. Asumir la libertad no simplemente como un ideal que se invoca en una sociedad por vía democrática, sino libertad como materiales, técnicas y prácticas gubernamentales de gobierno de la población que tienen un tipo de concreción específica en la escuela: una escuela en la cual los niños no reconocen la autoridad inapelable de sus maestros y éstos, sin confesarlo, terminan por ver a muchos de sus estudiantes como malpariditos incontrolables. 


\section{Discusión final La relación paz y escuela: historia de la educación como ejercicio}

Las tres escenas permitieron mostrar que en los excesos escolares (de maestros o alumnos) subyace una estrategia de gobierno de la población: producir la libertad que la gubernamentalidad liberal requiere para mantener su vigencia como forma general del poder. La escuela, aparentemente una institución disciplinaria y de encierro, genera prácticas y discursos que, en tiempos largos, producen efectos diferentes a los que a primera vista logran verse: lo que inicialmente parece castigo, verticalidad y disciplinamiento, a largo plazo se muestra como el sustrato profundo de la producción de su opuesto absoluto: la libertad fáctica y mental de las personas y de los grupos.

Pero la producción constante de la libertad también genera desbordes, como los traídos por las escenas, los cuales han llegado a configurar fenómenos como el "matoneo" en una escuela violenta. La libertad implica reconocer como constitutivos de la sociabilidad estos fenómenos, porque la libertad misma es la consecuencia de la necesidad de contar con dispositivos de seguridad para controlar estos desbordes: un dispositivo de seguridad sólo puede funcionar bien con la condición de que se dé algo que es justamente la libertad (Foucault, 2006: 71). Lograr que la libertad de unos no ponga en riesgo la de otros representa grandes costos de seguridad (Foucault, 2007: 86). Por lo tanto, que la escuela hoy parezca vertical y anquilosante, mediante fenómenos de violencia, exclusión, medicalización y homofobia, entre otros, produce parte de la libertad que el sistema necesita para continuar renovándose, es decir, para hacer cada vez más libres a las personas. ${ }^{4}$

La escuela produce la libertad liberal, se ha comprobado. Pero ahora, ¿cómo podría esa escuela, cada vez más conflictiva, violenta y terapéutica, con un talante discriminador y homofóbico consolidar en Colombia una paz duradera? (Echeverri, 2015; Román y Murillo, 2011; Unesco, 2015). En otras palabras, ¿cómo puede producir paz un dispositivo que, aparentemente, él mismo requiere ser pacificado para consolidar una mejor democracia? La respuesta es sencilla y a la vez compleja: lo puede hacer porque la educación es un ejercicio inmunitario de la sociedad para garantizar la permanente viabilidad de la especie humana.

No es lo mismo educación que escuela: la educación es un fenómeno a escala de la especie (Leroi - Gourhan, 1971; Sloterdijk, 2012; Sloterdijk, 2013), mientras la escuela es un fenómeno reciente de la modernidad. Por lo tanto, la forma escuela no puede dar cuenta de

${ }^{4}$ Que la escuela discrimine la sexualidad juvenil no es una prohibición taxativa sino del mecanismo que hace hablar de esas sexualidades para encontrarle salidas más amplias en la sociedad. La pregunta no es por qué la escuela las estigmatiza, sino por qué la escuela habla cada vez más de ellas (Foucault, 2008). 
lo educativo en su totalidad. Más aún, es menester reconocer que en términos generales "la escuela hace poco" por la sociedad. Sin embargo, de inmediato hay que reconocer "que hace poco, pero hace" (Baudelot y Leclercq, 2008). Esto es, si bien no construye los ideales de una sociedad, coadyuva a decantarlos en un repetido ejercicio con efecto inmunizador. Es por ese poco que la escuela hace que se debe insistir hasta el cansancio lo que se espera de ella: en esa repetición se producen las lentas transformaciones de la sociedad en relación con los ideales propuestos.

Así, pues, la escuela cumple una función inmunitaria en lógicas de repetición: por un lado, incuba formas morigeradas de problemáticas sociales para que su microescenificación prevenga daños mayores en el cuerpo social (Sloterdijk, 2012, 2013); por el otro, la escuela es un refugio de constante esperanza social de renovación, restauración de los lazos sociales para la construcción de horizontes vitales para los grupos y, consecuentemente, para la humanidad. Es decir, siempre se convierte en una válvula de escape de las cerrazones sociales: se espera que en la escuela vuelven a germinar las semillas para un inicio social renovado. Esto es, que mientras las condiciones sociales se estabilizan políticamente, la escuela crea los estados mentales para hacer posibles las transformaciones definitivas en términos de cultura (Nussbaum, 2012).

Que una sociedad con deseos de salir de la guerra vuelva la mirada a la escuela en busca de opciones no es imputarle a ésta responsabilidades en relación con lo que ella no provocó, sino reconocer su función de reconstituir los lazos sociales mediante ejercicios de repetición constante: que la escuela repita paz, paz, paz, a primera vista puede parecer un distractor para evitar nombrar los causantes reales de los conflictos, pero en realidad esos diferentes ejercicios pueden, en tiempos largos, producir cada vez mejores prácticas en relación con ese discurso. Empero, como la educación no es solo la escuela, el esfuerzo social tiene que apuntar a alinear con los ejercicios de la escuela otros aspectos de la sociedad, como la política y la economía, para que los efectos sean reconocibles y verificables.

En relación con la construcción de la paz hay que hacer el ejercicio de continuar repitiendo: "la escuela hace poco, pero hace" (Baudelot y Leclercq, 2008). Seguir apostándole a la escuela como estrategia inmunitaria con la cual la sociedad ensaya experiencias para que la humanidad continúe su aventura vital por lo abierto. Lo que dio pie para reconocer esta necesidad de apostarle a la escuela como escenario para consolidar una paz duradera fue preguntar por las formas de construcción de la libertad mediante mecanismos históricos que parecieran ir en contra de lo que requieren producir: el disciplinamiento vertical y las manifestaciones violentas de los estudiantes son excesos, ciertamente, pero de una lógica que busca la producción de la libertad liberal.

Después de esta comprobación ¿qué se sigue desde el punto de vista de la historia de la educación? Se requiere hacer una historia direccionada teóricamente que conjugue los 
presupuestos de la gubernamentalidad liberal, aquí expuestos, con las ideas de Peter Sloterdijk sobre la aventura vital humana en clave ejercitante. Esto es, que la necesidad de paz de una sociedad como la colombiana no voltee hacia la escuela con mirada juzgadora porque no previno los males de la sociedad, ni para forzar intervenciones coyunturales sin mayor efecto que su propia realización. Se debe recurrir a la historia para reconocer que ese poco que la escuela hace podría comprenderse mejor si se indaga por la función inmunitaria de la educación y el tipo de ejercicios que ella despliega para darle sentido a las personas y las culturas frente un mundo abierto y con un futuro desconocido.

Si la comprobación de algunos problemas actuales de la escuela como matoneo y violencia no son la negación de la libertad sino la consecuencia poco visible de formas históricas de obligar a las personas y a los grupos de ser cada vez más libres para garantizar el refinamiento y la vigencia de las formas liberales del poder, de similar manera un trabajo histórico dedicado debe reconocer los guiños de la filosofía para indagar qué género de ejercicio representa la educación en su forma escuela, y qué tipo de inmunización garantiza ésta para que la sociedad, pese a sus prácticas de guerra y exterminio, pueda regenerarse y construir vida donde la muerte funda su imperio. En fin, el guiño para los historiadores de la educación es emprender una investigación de la educación en clave ejercitante.

\section{Fuentes}

Archivos

AHAA Archivo histórico de Armenia, Antioquia: Alcaldía. 1926. Oficio № 25. Depto. de Antioquia. Agosto 16

AHA Archivo Histórico de Antioquia: Gobierno Provincial, 1856, Tomo 1806

APUA Archivo de Prensa Universidad de Antioquia

Informe del Secretario de Gobierno 1883, Popayán, FM/ 272

El Fósforo. Popayán. 1823: $n^{\circ} .152$

El Preceptor, Medellín. 1877, $\mathrm{n}^{\circ} .2$.

El repertorio escolar. Bogotá. 1870.

La Escuela Normal. Bogotá.1871. Tomo II.

La Escuela Primaria, 1873. Socorro, $n^{0} 79$.

Escuela Primaria, 1873. Socorro. $n^{\circ} 8$

El Pestalozziano, 1876. Socorro. $n^{\circ} 17$.

El Pestalozziano, 1876, Socorro. $n^{\circ} 18$

Diario político de Santa Fé de Bogotá. 1810. № 1 .

Bibliografía

Agamben, Giorgio (2016), Che cos `è un dispositivo?, Nottetempo, Roma.

Ardila, Héctor y Inés Vizcaíno (2008), Hombres y mujeres en las letras colombianas, Magisterio, Bogotá. 
Báez, M. (2006), La educación en los orígenes republicanos de Colombia, Universidad Pedagógica y Tecnológica de Colombia, Boyacá.

Baudelot, Ch. y F. Leclercq (2008), Los efectos de la educación, Del Estante Editorial, Buenos Aires.

Belalcazar, Ligia (1935), "Las modernas orientaciones educativas", Educación, vol. 3, núm. 18-19, enerofebrero, pp. 58-69.

Cajiao, Francisco (1994), Poder y justicia en la escuela colombiana, Fundación FES, Cali.

Carrasquilla, Ricardo (1927), Lo que va de ayer a hoy, La luz, Bogotá.

Castillo, Elizabeth y Carlos Sánchez (2003), "¿Democratizar la escuela o escolarizar la democracia? Dilemas de la socialización política en la escuela colombiana", Revista Colombiana de Educación, núm. 45, julio-diciembre, pp. 144-164.

Caruso, Marcelo, Pablo Pineau y Inés Dussel (2001), La escuela como máquina de educar. Tres escritos sobre un proyecto de Modernidad, Paidós, Buenos Aires.

Caruso, Marcelo y Eugenia Roldán (2005), "Pluralizing Meanings: the Monitorial System of Education in Latin America in the early nineteenth century", Paedagogica Historica, vol. 41, núm. 6, pp. 645-654.

Cubillos, Julián (2007), Agustín Nieto Caballero y el proceso de apropiación del pensamiento pedagógico y filosófico de John Dewey, Universidad del Valle-Cimnasio Moderno de Bogotá, Bogotá.

Deleuze, Gilles (1991), "Posdata sobre las sociedades de control", en Christian Ferrer (coord.), El lenguaje literario, t. 2, Nordan, Montevideo. pp. 114-121

Echeverri, Guillermo, Beatriz López, Juan Echeverri et al. (2007), Formar el pensamiento científico y tecnológico: una propuesta de integración para la Educación Básica, Universidad Pontificia Bolivariana, Medellín

Echeverri, Juan (2007), "Democracia liberal y escuela: de la disciplina al conflicto", en VIII Congreso Iberoamericano de la Educación Latinoamericana. Memorias, Buenos Aires, pp.135-151.

Echeverri, Juan (2011), "Liberalismo y la educación en los albores del siglo xIX en Colombia", Analecta politica, vol. 1, núm. 1, julio-diciembre, pp. 141-174.

Echeverri, Juan (2015), Escuela y Métodos Pedagógicos en clave de gubernamentalidad liberal. Colombia 1821-1946, Universidad Pontificia Bolivariana, Medellín.

Foucault, Michel (1990), Vigilar y Castigar, Siglo XXI Editores, México.

Foucault, Michel (2006), Seguridad, territorio, población, Fondo de Cultura Económica, México.

Foucault, Michel (2007), Nacimiento de la biopolítica, Fondo de Cultura Económica, México.

Foucault, Michel (2008), Las tecnologías del yo, Paidós, Buenos Aires.

García M., G. (1996), Por un país al alcance de los niños, Colombia al filo de la oportunidad-Misión de Ciencia, Educación y Desarrollo-Tercer Mundo Editores, Bogotá.

González, Carlos (1996), Autoridad y autonomía, Cuadernos Académicos 1, Medellín.

Heidegger, Martín (1994), Serenidad, Universidad Nacional de Colombia, Bogotá.

Hernández De Alba, Guillermo (1976), Documentos para la Historia de la Educación en Colombia, Patronato Colombiano de Artes y Ciencias, Bogotá.

Jares, Xavier (1997), "El lugar del conflicto en la organización escolar", Revista Iberoamericana de Educación, núm. 15, febrero, pp. 38-45.

Kant, Immanuel (1985), Tratado de pedagogía, Rosaristas, Bogotá.

Leroi -Gourhan, André (1971), El gesto y la palabra, Universidad Central de Venezuela, Caracas.

López, Beatriz y Guillermo Echeverri (2006), "Democracia y estatuto del maestro. Culpa neoliberal y ecos de modas intelectuales", en AA. VV., Los Bordes de la pedagogía: del modelo a la ruptura, Universidad Pedagógica Nacional, Bogotá, pp. 205-214.

Luzuriaga, Lorenzo (1969), Origen de las Ideas Educativas de Bolívar y Simón Rodríguez, Universidad Central de Venezuela, Caracas. 
Manual del sistema de enseñanza mutua (1826), Manual del sistema de enseñanza mutua aplicado a las escuelas primarias de los niños, Impreso por S.S, Fox, Bogotá.

Martínez, Alberto (1986), Escuela, maestro y métodos en Colombia 1767-1820, Universidad Pedagógica Nacional, Bogotá

Martínez, Alberto (1994), "La educación en el Nuevo Reino de Granada", en Buenaventura Delgado (coord.), Historia de la educación en España y América, vol. II, Morata-Fundación Santa María, Madrid, pp 346-356

Nussbaum, Martha (2012), Crear capacidades. Propuestas para el desarrollo humano, Paidós, Barcelona. Pestalozzi, Johann (1997), Cómo Gertrudis enseña a sus hijos, Miguel Ángel Porrúa, México.

Román, Marcela y Javier Murillo (2011), "América Latina: violencia entre estudiantes y desempeño escolar", Revista Cepal, núm. 104, agosto, documento pdf disponible en: <www.cepal.org/publicaciones/xml/3/44073/RVE104RomanMurillo.pdf> (fecha de consulta: 12/06/2013).

Rose, Nikolas (2010), Powers of Freedom. Reframing political thought, Cambridge University Press, Cambridge. Sáenz, Javier, Óscar Saldarriaga y Armando Ospina (1997), Mirar la infancia: Pedagogía, moral y modernidad en Colombia, 1903-1946, vol. I y II, Asociación de Editoriales Universitarias de Colombia, Bogotá.

Saldarriaga, Óscar (2003), Del oficio del maestro. Prácticas y teorías de la pedagogía moderna en Colombia, Magisterio, Bogotá

Sanabria, Francisco (2010), "Enseñando mutuamente: una 'aproximación' al método lancasteriano y a su apropiación en Colombia", Revista Historia de la Educación Colombiana, vol. 13, núm. 13, pp. 47-76.

Sloterdijk, Peter (2012), Has de cambiar tu vida, Pretextos, Madrid.

Sloterdijk, Peter (2013), Muerte aparente en el pensar. Sobre la filosofía y la ciencia como ejercicio, Siruela. Barcelona.

UNESCO (2015), El bullying homofóbico y transfóbico en los centros educativos. Taller de sensibilización para su prevención: guía de facilitación, Oficina Regional de Educación para América Latina y el Caribe (OREALC/UNESCO), Santiago, documento pdf disponible en: <http://unesdoc.unesco.org/ images/0024/002448/244841s.pdf>, (fecha de consulta: 3/09/2015).

Uribe, José Antonio (1927), Instrucción Pública. Disposiciones vigentes. Exposición de motivos, Imprenta Nacional, Bogotá.

Varela, Julia (1995), Categorías espacio-temporales y socialización escolar: del individualismo al narcisismo. Escuela, poder y subjetivación, La Piqueta, Madrid.

Valencia, Guillermo (s.a.), Poemas, Claridad, Buenos Aires.

Vega Vargas, Diana M. (2011), "La ciudad de los Niños. La Infantilización de la Sociedad: una Referencia a Tonucci", Buenas Tareas. Documentos de Investigación, documento html disponible en: <http:// www.buenastareas.com/ensayos/La-Ciudad-De-Los-Ni\%C3\%Blos-La/1743088.html> (fecha de consulta: 15/04/2016)

Weinberg, Gregorio (1983), "Las ideas lancasterianas de Simón Bolívar y Simón Rodríguez", ponencia presentada al Congreso sobre pensamiento político latinoamericano, Caracas, Venezuela, 26 de junio al 2 de julio, documento pdf disponible en: <http://www.educ.ar/dinamico/UnidadHtml_ get_43eda445-7a06-1lel-82bb-ed15e3c494af/las_ideas_lancasterianas.pdf>, (fecha de consulta: 9/03/2014).

Zuluaga, Olga (1979), Colombia: dos métodos de su práctica pedagógica durante el siglo xIx, Universidad de Antioquia, Medellín.

Zuluaga, Olga (1984), El maestro y el saber pedagógico en Colombia, Universidad de Antioquia, Medellín. Zuluaga, Olga (2001), "Entre Lancaster y Pestalozzi: los Manuales para la formación de Maestros en Colombia, 1822-1868", Revista Educación y Pedagogía, vol. 13, núm. 29-30, pp. 41-49. 
Juan Carlos Echeverri, Magíster en Historia, doctor en Educación en la Línea Historia de la Educación, docente titular de la Universidad Pontificia Bolivariana, Medellín, Colombia y Coordinador del Grupo de Investigación Pedagogía y Didácticas de los Saberes (PDS). Sus líneas de investigación son: Historia de la Educación, Enseñabilidad de las ciencias, disciplinas y saberes y Educabilidad del sujeto. Sus recientes publicaciones tituladas Escuela y Métodos Pedagógicos en clave de gubernamentalidad liberal. Colombia 1821-1946 (2015), "Investigación y escritura de maestros en Medellín: una comunidad interniveles educativos que In-Mova" en Encuentro con-sentido pedagógico. Investigación educativa un horizonte político de ciudad (2015) y "Hacer Historia de la Educación con el Influjo del Grupo Historia de la Práctica Pedagógica en Colombia" en Revista História da Educação, vol. 17, núm. 39, eneroabril, 2013.

Recibido: 21 de octubre de 2016

Aceptado: 29 de noviembre de 2016 